\title{
STARTING ASSISTANCE DEVICE FOR DIRECTLY-DRIVEN ELECTRIC VEHICLE WITH VARIABLE-IDLE SPEED CONTROL
}

\author{
Ping Xiong, Chenglin Gu
}

Original scientific paper By introducing a novel permanent magnetic bi-stable electromagnetic clutch unit (PMBECU) in the driveline of directly-driven electric vehicle, a flexible connection between motor and hub is realized with characteristic of separated starting process of drive motor and wheel load. Firstly, the working principle and power supply scheme for the PMBECU is discussed. Then the assembly for the wheel-drive system with starting assistance device by the clutch is investigated. Considering the good dynamic performance of wheel motor, variable-idle speed scheme is presented and the simplified model for fast clutch engagement is built and analyzed. Finally, the proposed method for directly-driven electric vehicle launch is performed on the test rig. The experimental results indicate the shock intensity and electromagnetic impulsion during the starting process is decreased effectively by clutch-coupling startup, which results in good driving comfort and less heat in armature winding of drive motor.

Keywords: clutch unit; directly-driven electric vehicle; driving comfort; starting assistance; variable-idle speed control

Pomoćni uređaj za pokretanje direktno pogonjenog električnog vozila s regulatorom brzine praznog hoda motora

Izvorni znanstveni članak Uvođenjem nove trajne magnetski bi-stabilne elektromagnetske spojke (PMBECU) u transmisiju direktno pogonjenog električnog vozila, ostvarena je fleksibilna veza između motora i glavine karakteristična po odvojenom pokretanju pogonskog motora i osovinskog opterećenja. Najprije se raspravlja o načinu rada i shemi dovoda energije za PMBECU. Zatim se istražuje sklop za sustav pogona kotača s uređajem za pokretanje pomoću spojke. Razmatrajući dobre dinamičke karakteristike motora kotača, daje se shema promjenljivog praznog hoda te se gradi i analizira pojednostavljeni model za brzo ukapčanje spojke. Konačno se predložena metoda za pokretanje direktno pogonjenog električnog vozila primijenjuje na uređaju za ispitivanje. Eksperimentalni rezultati pokazuju da su jačina udara i elektromagnetski impuls tijekom pokretanja efikasno smanjeni pokretanjem zupčaste spojke, što rezultira udobnošću u vožnji i manjim zagrijavanjem namotaja armature pogonskog motora.

Ključne riječi: direktno-pogonjeno električno vozilo; pomoć kod pokretanja; regulator brzine praznog hoda; sklop spojke; udobnost u vožnji

\section{Introduction}

Great attention has been paid on electric vehicle (EV) since the problems of environmental pollution and energy crisis issues became increasingly prominent [1, 2]. Compared with centralized-driven electric vehicle, the directly-driven $\mathrm{EV}$, realizing the direct transmission from drive motor to the vehicle load, has features such as compact structure (no gearbox), flexible control (independently driven), and high transmission efficiency (less mechanical loss), according to the new direction of EV [3]. But, due to the rigid connection between the hub and drive motor, static starting resistant torque is required to be overcome when vehicle starts from standstill. Moreover, back electromotive force (EMF) in the armature will be induced when electric vehicle suddenly brakes, which in turn may damage the power device and hall sensors. Thus, it brings both electromagnetic impulsion and mechanical shock inevitable especially at the time of starting and stopping moment of vehicle.

\subsection{Value of clutch mechanism in power train}

In practical application, subjected to the uncertainties about road conditions, the utilization of mechanical clutch in the power train of traditional automobile is to realize a smooth clutch engagement during vehicle starting or shifting.

A fast and smooth clutch engagement control for mechanical hybrid power train is discussed in [4], and optimal controller for startup of AMT trucks is presented in [5]. Both of them focus on reducing shock intensity and improving the driving comfort of vehicle. Optimized controller for track of engine throttle and displacement control of mechanical clutch is designed to coordinate the friction work of clutch and driving comfort [6]. Through the speed control of the induction machine and the diesel engine, an advanced gear-shifting and clutching strategy is designed to decrease mechanical shock [7].

The clutch mechanisms are also applied to remit electromagnetic impulsion of drive motor in starting conditions. Centrifugal clutch is proposed to assist startup of electric motor. Its basic principle is to employ speed of its own to engage or disengage the load automatically at a certain speed, which results in the reduction of residence time of electromagnetic impulsion and accumulated heat in armature winding during the startup of electric motor with load [8, 9].

Furthermore, with the introduction of clutch function into the driveline of vehicle, the problems of losses while coasting or the startup failure of vehicle with normal clutch operation under special road conditions, such as clay soil, wheel sinkage, can be solved. The action of quick clutch engagement is applied at the moment the engine speed is held at high speed while the vehicle is stationary, utilizing kinetic energy of fly-wheel for vehicle launch $[10,11]$.

In most of the above methods, although different types of clutch are widely used in ordinary internal combustion engine vehicle or other traction occasions, restricted by the fixed idle speed of engine, it may cause stalling of engine by operation of abrupt startup and discomfort feelings to driver without appropriate idle speed adjustment. And the controller design for the displacement control of clutch engagement as described in $[5,6]$ is sensitive to the parameters, such as coefficient 
of friction disk, displacement of diaphragm spring or time constants for the actuator dynamics, etc., somehow reducing the performance of system. And the engaging speed of centrifugal clutch is usually fixed without considering the actual load conditions.

\subsection{Main contribution and outline}

The traditional mechanical friction clutch or the centrifugal clutch used in aforementioned literature, generally have large size and are difficult to be installed due to the limited space between hub and motor. Meanwhile, mechanically controlled clutch is basically centralized-driven, which is not in accord with independently driven mode for each wheel-motor separately. Moreover, common electromagnetic clutch is energy-consuming for maintaining coil energized with electric current in operating status, which decreases the battery range. Therefore, a novel permanent magnetic bistable electromagnetic clutch unit featured by compact structure, flexible control and bi-stable status without any energy consuming at stable status, is designed. And a new starting method is proposed for directly-driven EV, highlighted by the separated starting process for motor and wheel load in this paper. Correspondingly, the working principle and clutch engagement process of the new type clutch unit is discussed respectively.

Unlike controlling the displacement profile of clutch, this paper presents a simplified clutch model based on the momentum conservation during rapid clutch engagement. And suitable mismatch speed of master and slave side at the right time of clutch engagement should be considered according to the wheel load for assuring both comfort level and starting current.

\section{New-type clutch unit and its working principle}

The assembly of the new type clutch unit to realize the flexible connection between hub and motor is shown in Fig. 1. The working principle of clutch unit is described as follows: the clutch unit remains in 'closed' or 'open' state when the coil is un-polarized (switch off). Subjected to electromagnetic stress and repulsion produced by the permanent magnet mounted polarity opposite from two sides when the control coil is switched on, the mover transfers from 'open' into 'closed' state. And it can automatically cut off the power supply through position sensor, then one clutch engagement for the master and slave side is completed and vice versa. The prototype is verified and optimized by our group $[12,13]$.

The clutch unit mentioned above has a flat structure and it is easy to be installed in the restricted space between wheel motor and hub, which creates integration design scheme for wheel-drive system with such an electromagnetic clutch unit. Then, through the specific design for the push rod, an actuator similar to dog clutch or frictional clutch is formalized for power transmission and interruption between motor shaft (master side) and wheel load shaft (slave side). Due to additional position sensors and requirement of slip ring by dc supply for the control coil, it somehow reduces the reliability of the whole system. Considering the fact the clutch units merely need power supply at the instant time when they start to be engaged or disengaged to the slave side. Hence, the small current pulse supply theme is proposed, characterized with simple structure (without position sensors and slip rings) and more reliability (automatic switch off power supply).

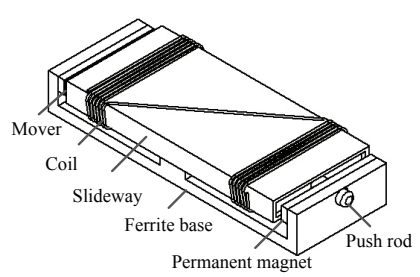

(a)

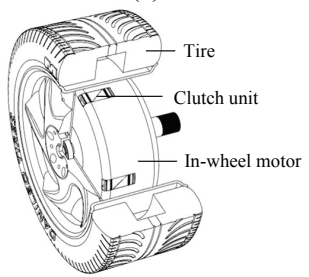

(b)

Figure 1 Prototype of PMBECU and its assembly between hub and motor for in-wheel drive

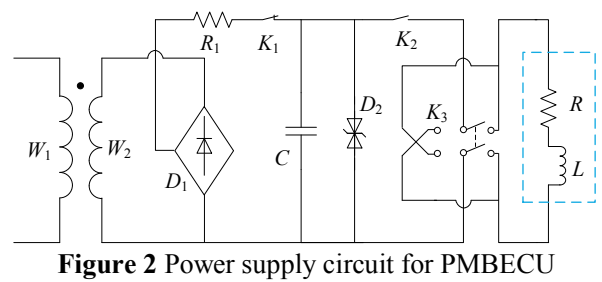

The specific control schematic diagram is described in Fig. 2.The resistor $R$ and inductance $L$ represent the control coil of clutch unit. $D_{1}$ is the bridge rectifier, the input of which can be from the harmonic EMF of winding $W_{2}$ located in the air gap of wheel motor. $C$ is the pulse capacitor; $R_{1}$ is the current limiting resistance. $K_{1}$ and $K_{2}$ is interlock switch and $K_{3}$ represents the current reserving key. The DC source charges the capacitor when $K_{1}$ is switched on and $K_{2}$ switched off. Reversely the capacitor discharges to the coil when $K_{1}$ is switched off and $K_{2}$ swiched on. By controlling the $K_{3}$, the control coil acquires the conventional current flow for the clutch engagement and disengagement.

With the assiatance of such a special clutch unit for the wheel-drive system, the scheme for seperated starting process of motor and wheel load is developed for the purpose of decreasing the electromagnetic impulsion and increasing the driving comfort.

\section{Variable-idle speed control strategy and simulation 3. 1 Modelling of driveline dynamics 3.1.1 Vehicle dynamics}

The vehicle driving resistance of entire vehicle mainly consists of four parts: road friction, aerodynamic drag, grade force and acceleration [14]. Ignoring small aerodynamic drag when vehicle is launched from rest, the vehicle model can be simplified as:

$F=F_{i}+F_{r}=M_{\mathrm{v}} g \sin \varphi+\mu M_{\mathrm{v}} g$ 
where $\mu$ is the coefficient of rolling resistance, $M_{\mathrm{v}}$ is the mass of $\mathrm{EV}, g$ is the gravity acceleration, $\varphi$ is the slope angle, $F_{\mathrm{i}}$ is the grade resistance, $F_{\mathrm{r}}$ is the rolling resistance. Typically, rolling friction was increased by flange contact and by sand or leather on surfaces, while the road surface roughness raises static resistance with non-obvious effect on kinetic [15]. In addition, static frictional resistance like bearing drag needs to be considered for frequent starting and stopping conditions. Consequently, the symbol $\mu_{\mathrm{s}}$ represents the coefficient of static rolling resistance, which is different from $\mu_{\mathrm{rr}}$, the dynamic coefficient when vehicle starts motion. And the static coefficient of rolling friction can reach $2 \div 3$ times as much as dynamic one in some conditions [16]. It produces additional resistance torque when vehicle starts from such road conditions.

\subsubsection{Ideal clutch model}

Various types of clutch are used for vehicle gear shifting, motorcycle and vehicle startup, but the process of clutch engagement or disengagement is similar. The tractive force is transmitted to the driven wheel directly through clutch while clutch is closed and there is no power transmission while clutch is open. Analogous to ideal electrical switches, an ideal mechanical clutch or dog clutch coupling is engaged and disengaged between two rotating masses at different speeds instantaneously. Then the paper treats such an event as a perfectly inelastic collision and calculates the common speed after collision based on the conservation law of angular momentum [17]. Accordingly, the ideal clutch model is described by:

$$
J_{\mathrm{m}} \omega_{0}=\left(J_{\mathrm{m}}+J_{\mathrm{v}}\right) \omega_{1}
$$

where $J_{\mathrm{m}}$ is the moment of inertia of motor, $J_{\mathrm{v}}$ the equivalent moment of inertia of vehicle load, $\omega_{0}$ the zeroload angular speed and $\omega_{1}$ the instantaneous angular speed when clutch is locked. Once the speed difference of shaft between master and slave side has been reduced to zero, then wheel load is flexibly coupled to drive motor by clutch, behaving like a linking element. The mechanical equation at engaged phase can be written as:

$$
\left(J_{\mathrm{v}}+J_{\mathrm{m}}\right) \frac{\mathrm{d} \omega}{\mathrm{d} t}=T_{\mathrm{e}}-T_{\mathrm{L}}
$$

where $T_{\mathrm{e}}$ is the driving torque, $T_{\mathrm{L}}$ is the load torque. Consequently, an initial speed is obtained by both two sides when the clutch is completely closed. Accordingly, the corresponding static coefficient of resistance turns into dynamic coefficient of rolling resistance after clutch engagement. Then the required traction torque for overcoming the vehicle load turns into dynamic rolling resistance, which reduces the demanded transmitted torque at the clutch closure time to accelerate the wheel load to some extent.

\subsection{Evaluation index for driving comfort and control objectives}

Vehicle drivability is important aspect for evaluating the smoothness of vehicle launch and shifting, which is subject to driver's subjective perception of that behavior. Previous researches indicate that peak-to-peak acceleration and jerk (change rate of acceleration) are the key factors which determine the shift quality or drivability performance [18]. Ignoring vertical and horizontal vibration, most of researches at present evaluate the performance of vehicle shifting or starting process objectively by measuring rate of the change of vehicle longitudinal acceleration, the so-called jerk. Generally, the absolute value of jerk level is recommended to satisfy $|\dot{a}| \leq 10 \mathrm{~m} / \mathrm{s}^{3}$, which indicates good driving comfort [19, 20].

The inappropriate mismatch speed of master and slave side when the clutch begins to be engaged can also lead to unpleasant feelings to drivers. It is therefore necessary to guarantee the smaller acceleration variation before and after the synchronization. Hence, the idle speed of motor should be chosen adequately on the basis of actual load torque for the following objectives:

- the torque transmitted by motor should be greater than load torque for the purpose of continuous acceleration after the clutch lock-up

- $\quad$ ensuring the continuity of acceleration at the lock-up time instant, say $t$, for the purpose of comfort level and restricting the transient jerk when clutch begins to be engaged

\section{3 Variable-idle speed control strategy}

The idle speed when the clutch is engaged to slave side is initially given based on the fitted curves according to starting resistance torque which is measured offline with implementation of clutch-coupling startup. In practical application, starting resistance can be approximately estimated from the sensors or the initial brake pedal displacement when the vehicle is launched on a slope from standstill. Moreover, in some modern trucks, GPS signals and grade sensors can also be used to obtain the grade angle, and then improve the estimation accuracy of resistance torque [5]. The specific control flowchart for idle speed control strategy is shown in Fig. 3.

As mentioned above, the synchronizing phase complies with angular momentum and theorem of impulse for the action of rapid clutch engagement. Hence, the equivalent average angular acceleration is given by:

$$
\frac{\Delta \omega}{\Delta t}=\frac{\bar{M}}{J_{\mathrm{v}}}
$$

where $\bar{M}$ is the equivalent average torque, $\Delta t$ is the synchronization time, $\Delta \omega$ is the change of angular velocity. The jerk value is calculated by defined equation:

$\dot{a}=\frac{\mathrm{d} a(t)}{\mathrm{d} t}$

Direct calculation of jerk by definition (5) will introduce high frequency contents, given the fact that a very fixed step for numerical simulation is generally less than $1 \mathrm{~ms}$. Meanwhile, relative researches conclude that human beings are more sensitive to $10 \div 14 \mathrm{~Hz}$ oscillations 
and there is no uncomfortable feeling to longitudinal shocks above $50 \mathrm{~Hz}$ in [21].

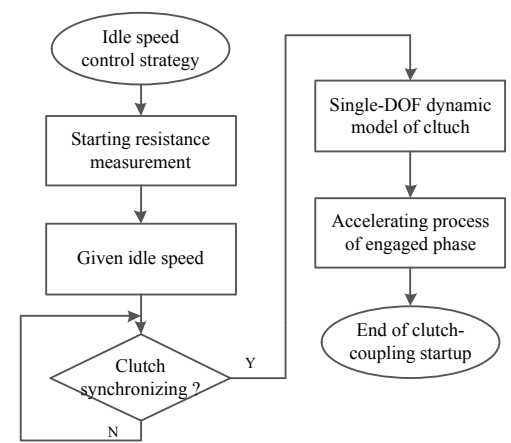

Figure 3 Flowchart of variable-idle speed control strategy

For this reason, the average jerk is used for the evaluation of shock intensity with the sampling period $100 \mathrm{~Hz}$ in this paper. Combining Eq. (2), Eq. (4) and Eq. (5), the average jerk value for preserving a good comfort level while clutch begins to be engaged to slave side should be satisfied by:

$$
\dot{a}=\frac{J_{\mathrm{m}}}{J_{\mathrm{m}}+J_{\mathrm{v}}} \frac{r_{\mathrm{w}} \omega_{0}}{\Delta t \cdot T_{\mathrm{s}}} \leq \pm 10 \mathrm{~m} / \mathrm{s}^{3}
$$

where $a$ is the longitudinal acceleration, $T_{\mathrm{s}}$ the sampling period, $r_{\mathrm{w}}$ the tire radius of the EV. And the discontinuity in the slave side shaft acceleration at the clutch lock-up time $t$ is proportional to the slip acceleration just before clutch closure, and is given in [22]:

$$
\left\{\begin{array}{l}
\dot{\omega}_{\mathrm{v}}\left(t^{+}\right)-\dot{\omega}_{\mathrm{v}}\left(t^{-}\right)=\frac{J_{\mathrm{m}}}{J_{\mathrm{m}}+J_{\mathrm{v}}} \dot{\omega}_{\mathrm{sl}}\left(t^{-}\right) \\
\dot{\omega}_{\mathrm{sl}}\left(t^{-}\right)=\dot{\omega}_{\mathrm{e}}\left(t^{-}\right)-\dot{\omega}_{\mathrm{v}}\left(t^{-}\right)
\end{array}\right.
$$

$\omega_{\mathrm{sl}}$ represents the slip angular acceleration, $\dot{\omega} \mathrm{v}_{\mathrm{v}}\left(t^{-}\right)$ and $\dot{\omega}_{\mathrm{v}}\left(t^{+}\right)$denote acceleration of clutch at the instant of pre-synchronization and post-synchronization. And $\omega_{\mathrm{e}}\left(t^{-}\right)$ stands for angular speed of DC motor just before clutch closure. Taking Eq. (7) into consideration, good driving comfort during the starting phase can be promised as long as the equation below is satisfied when vehicle is launched:

$$
\omega_{0} \in\left[0, \omega_{\max }\right]
$$

$\omega_{\max }$ is calculated from Eq. (6) and denotes the restricted idle speed for preserving good driving comfort level. At the other hand, the transmitted torque $T_{\mathrm{e}}$ at the clutch closure time must be larger than the load torque $T_{\mathrm{L}}$ for continuous acceleration as long as the transient jerk should be assured at the instant time $t$ when clutch is completely engaged:

$$
T_{\mathrm{e}}\left(t^{+}\right) \geq T_{\mathrm{L}}
$$

\section{4 Simulation and analysis}

Based on the dynamic models presented in the sections above, numerical simulations for vehicle launch under typical road conditions are carried out. Considering the fact the electric vehicle is powered by DC source, the DC motor is chosen as the power source for the whole driveline because of its simple control. The parameters of simulation models are listed in Tab. 1.

Since the vehicle mass is lumped together as one inertia to the drive motor shaft and air resistance is small enough to be neglected at very low vehicle speed, the starting resistance torque is mainly influenced by rolling and grade resistance. In general, the dynamic coefficient of rolling friction is about $0,01 \div 0,018$ in normal driving condition. However, static friction needs to be considered for vehicle launch, especially considering the frictional loss or additional resistance torque induced by special road conditions. The frictional coefficient of sliding bearing varies with the vehicle speed, as referred in [23], its value decreases with the increase of vehicle speed and tends to be dynamic frictional coefficient after reaching a certain speed. The experiments conducted in [24] indicate that increasing the velocity will reduce wheel sinkage and free rolling forces. Hence, taking static resistance torque from standing start into account, $\mu_{\mathrm{s}}$ is assumed to be 3 times of $\mu_{\mathrm{rr}}$ in simulation model.

Table 1 Simulation parameters of vehicle and DC motor

\begin{tabular}{|c|c|c|c|}
\hline Vehicle & Value & Motor & Value \\
\hline$M_{\mathrm{v}}(\mathrm{kg})$ & 1000 & $U_{\mathrm{N}}(\mathrm{V})$ & 60 \\
\hline$r_{\mathrm{w}}(\mathrm{m})$ & 0,3 & $I_{\mathrm{N}}(\mathrm{A})$ & 56 \\
\hline$G$ (gear ratio) & 1 & $L_{\mathrm{a}}(\mathrm{H})$ & 0,0022 \\
\hline$\mu_{\mathrm{s}}$ & 0,045 & $K_{\mathrm{e}}(\mathrm{V} \cdot \mathrm{s} / \mathrm{rad})$ & 1,027 \\
\hline$\mu_{\mathrm{rr}}$ & 0,015 & $n_{\mathrm{N}}(\mathrm{r} / \mathrm{min})$ & 540 \\
\hline-- & -- & $J_{\mathrm{m}}\left(\mathrm{kg} \cdot \mathrm{m}^{2}\right)$ & 0,5 \\
\hline
\end{tabular}

Furthermore, supposing the resistance torque under normal driving condition is equal to the rated torque of drive motor, the additional rated resistance will be added to the grade resistance with the increase of climbing angle by one degree. The total starting resistance torque can approach as much as $7 \div 8$ times to normal rated condition, even in a road angle at 5 degree. Since starting conditions are largely varied, it is unlikely suitable to implement current limiting control scheme for motor to accelerate wheel load from standstill.

Then full voltage starting method for electric motor is likely to be used for overcoming greater starting resistance without motor stalling under rigid connection. Note that variables with superscript $*$ stand for per unit value and rated value with subscript $\mathrm{N}$. The base value of current, and shock intensity are rated current and recommended jerk level $\left(10 \mathrm{~m} / \mathrm{s}^{3}\right)$ respectively in simulation. The results of direct startup with full voltage are shown in Fig. 4, and the maximal starting current is almost 20 times that of rated current. Detailed results at initial time of startup are shown in the subgraph of Fig. 4 and it indicates the drive motor starts to accelerate until the static resistance torque is overcome. Furthermore, the per unit value of jerk is far greater than recommended index which leads to uncomfortable feelings to drivers. 
Although better acceleration and adaptability of complicated working conditions is acquired by direct startup with full voltage, it will cause both mechanical shock and electromagnetic impulsion conversely, which directly influences comfort level or damages power quality and mechanical components of vehicle.

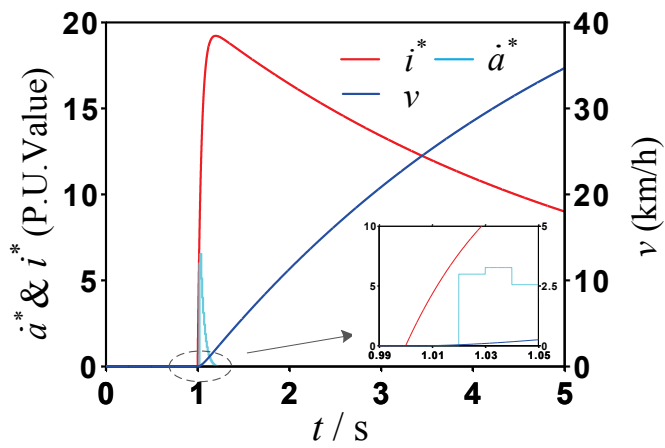

Figure 4 Simulation results of direct startup of EV with full voltage

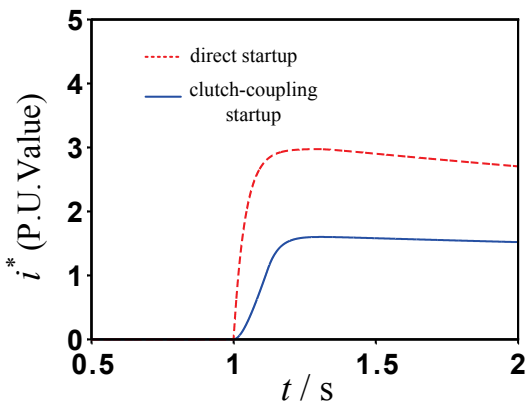

(a)

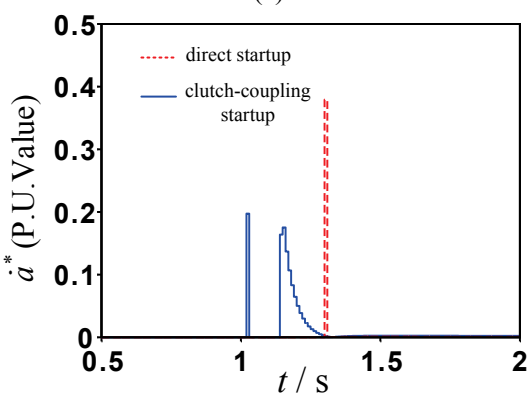

(b)

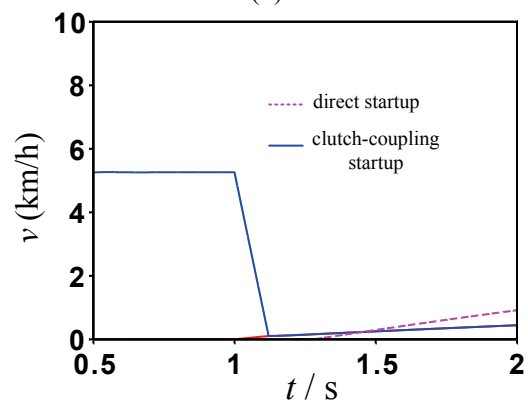

(c)

Figure 5 Comparison of direct startup and clutch-coupling startup under same condition: (a) Curves of armature current, (b) Curves of shock intensity, (c) Curves of motor and vehicle speed

In general, the maximum transient jerk and armature current can be decreased with reduced starting voltage, which in turn leads to longer starting time, even motor stalling in some circumstances. Theoretically, the time elapsed from standstill to movement is determined by: $t_{\mathrm{s}}=-\frac{1}{\tau_{\mathrm{a}}} \cdot \ln \left(1-\frac{T_{\mathrm{L}} R_{\mathrm{a}}}{u K_{\mathrm{T}}}\right)$

where $\tau_{\mathrm{a}}, K_{\mathrm{T}}$ are the electromagnetic time constant and torque constant of DC motor respectively, $R_{\mathrm{a}}$ is the armature resistance of DC motor.

In order to start the wheel load without motor stalling, the clutch-coupling mode for vehicle launch is implemented. Based on the optimized idle speed strategy discussed above, the optimal idle speed for clutch engagement will be obtained by enough transmitted torque for continuous load acceleration after clutch engagement while compromising the starting comfort.

Then under the rated condition, the comparison for two startup modes is discussed afterwards. The comparative results of armature current, jerk and speed by direct startup and clutch-coupling startup are shown in Fig. 5 . The mentioned idle speed $v_{0}$ is governed by:

$v_{0}=r_{\mathrm{w}} \omega_{0}$

The peak value of armature current and jerk value is decreased to about $50 \%$ of direct startup respectively under rated condition. From the velocity curves, the wheel load immediately accelerates when the clutch is engaged to the slave side at $1 \mathrm{~s}$, compared to the direct startup, the speed of which begins to increase till the static resistance torque is overcome. And the transmitted torque is about rated torque of drive motor while the time elapsed is about $(3 \div 4) \tau_{\mathrm{a}}$ after clutch engagement, as shown in Fig. $5 \mathrm{a}$. For comprehensive consideration, the smaller jerk and starting current is obtained with ideal idle speed about 6 $\mathrm{km} / \mathrm{h}$ under rated condition.

\section{Experimental results and analysis}

To verify the effectiveness of open-loop optimal control strategy for preserving the driving comfort and obtaining enough transmitted torque at the time of clutch closure, meanwhile, to compare the performance of the direct startup and clutch-coupling startup of vehicle, the test rig as shown in Fig. 6 is built for experimental research of clutch-coupling and direct startup for the whole driveline.

The experimental bench mainly consists of the following parts including DC motor, clutch assembly, clutch operator, disc brake and generator load. The utilization of different types of clutch has no difference on the simulation of clutch-coupling startup. For simplification, the specified clutch unit is replaced by the friction clutch in this paper for performing experiments of the separated starting process of wheel motor and load. The parameters of the DC motor are listed in Tab. 2. Note that variables $U_{\mathrm{f}}$ and $I_{\mathrm{f}}$ represent the rated filed voltage and current respectively.

Then the engagement or disengagement of master side and slave side is controlled by the clutch operator, and sudden clutch engagement for utilizing the kinetic energy of master is completed by quickly releasing the clutch operator. The steady or dynamic loading is controlled by the regulation of armature resistance of generator and frictional force of brake assembly. And the 
angular speed of master side and the load torque can be measured by transducer installed among the power train.

The induced armature voltage per unit speed is obtained by least squares curve fitting of experimental data. Thereupon the load speed of slave side can be calculated by measuring the armature voltage of generator. Acceleration is estimated from the measured speed signals of generator, using a differentiator in series with a first-order low-pass filter. And the jerk level is obtained by deriving the acceleration with respect to time.

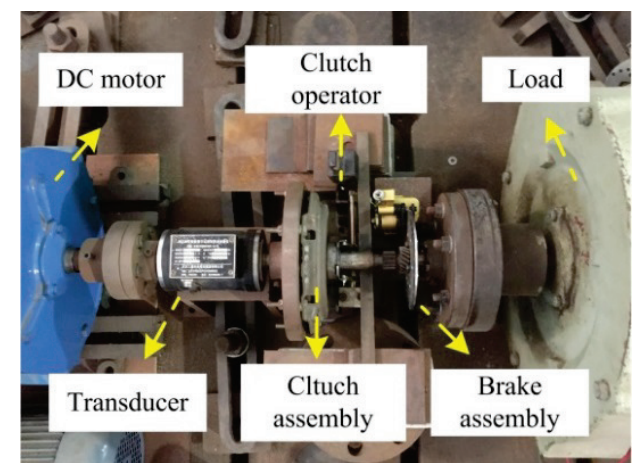

Figure 6 Test rig for simulating directly-driven EV launch

Table 2 Experimental parameters of drive motor

\begin{tabular}{|c|c|}
\hline Motor & Value \\
\hline$U_{\mathrm{N}}(\mathrm{V})$ & 110 \\
\hline$I_{\mathrm{N}}(\mathrm{A})$ & 35 \\
\hline$n_{\mathrm{N}}(\mathrm{r} / \mathrm{min})$ & 750 \\
\hline$R_{\mathrm{a}}(\Omega)$ & 0,412 \\
\hline$U_{\mathrm{f}}(\mathrm{V})$ & 220 \\
\hline$I_{\mathrm{f}}(\mathrm{A})$ & 1,36 \\
\hline$J_{\mathrm{m}}\left(\mathrm{kg} \cdot \mathrm{m}^{2}\right)$ & 0,4 \\
\hline
\end{tabular}

Generally, the max car speed is probably about $50 \div 60$ $\mathrm{km} / \mathrm{h}$ in consideration of urban drive cycle and battery life. So the input voltage of DC motor is limited to $60 \mathrm{~V}$ in this paper for ensuring the max velocity of the vehicle is around $50 \mathrm{~km} / \mathrm{h}$. The base values of current and velocity are rated current (35 A) and max vehicle velocity (50 $\mathrm{km} / \mathrm{h}$ ) respectively in experiment. Without considering influence by constant factors for calculating the vehicle jerk, the equivalent jerk $a_{\mathrm{d}}$, which is directly computed by the second derivative of angular speed, is considered for optimized process of idle speed control and transverse comparison of shock intensity for different startup modes in the following experiments.

Subjected to resistance torque induced by various load conditions or static friction in the case of vehicle startup, full voltage starting for DC motor is implemented. Then, the experiment for direct startup with given max voltage is carried out, and the corresponding curves of velocity, armature current, equivalent jerk are given in Fig. 7. The peak current is up to $84 \mathrm{~A}$, about 2,5 times of rated current. Meanwhile, the equivalent jerk level is up to $140 \mathrm{~m} / \mathrm{s}^{3}$. The experimental results basically agree with simulation results. The max jerk and armature current is reached instantly at the right time of starting moment. Although the fast load startup is acquired, it brings the electromagnetic impulsion and mechanical shock obviously.
From Eq. (6), the smaller idle speed to be engaged to the slave side usually results in good driving comfort. However, the negative acceleration will occur when the transmitted torque at the lock-up time is less than actual load torque. As shown in Fig. 8, the load speed decreased to zero after clutch engagement when the drive motor starts with an idle speed $3 \mathrm{~km} / \mathrm{h}$ under the same starting conditions with the load torque $6 \mathrm{~N} \cdot \mathrm{m}$.

Then the optimized clutch-coupling startup is done under the same load condition. From the contrast curves of equivalent shock intensity shown in Fig. 9, the load speed is increased quickly at the moment of clutch engagement by clutch-coupling startup, while the armature current of DC motor rises correspondingly. The armature current by clutch-coupling startup is lower than the one by direct startup in the whole starting process, which results in smaller armature winding heating of drive motor. About $1 / 2$ peak value of armature current and $1 / 4$ max jerk value is reduced respectively by the optimized idle speed control strategy. Compared with direct startup, quick startup for load without motor stalling is realized by clutch-coupling startup. The experimental results are consistent with the simulation.

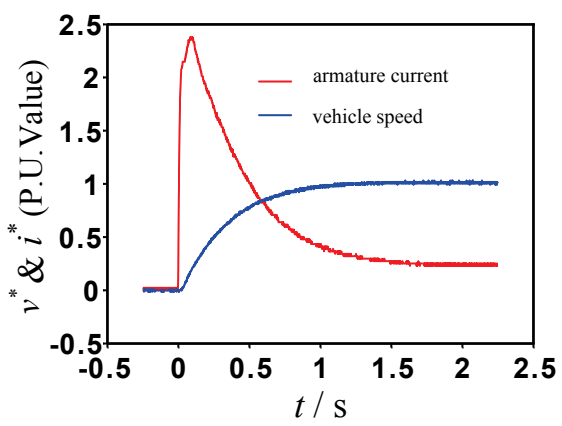

(a)

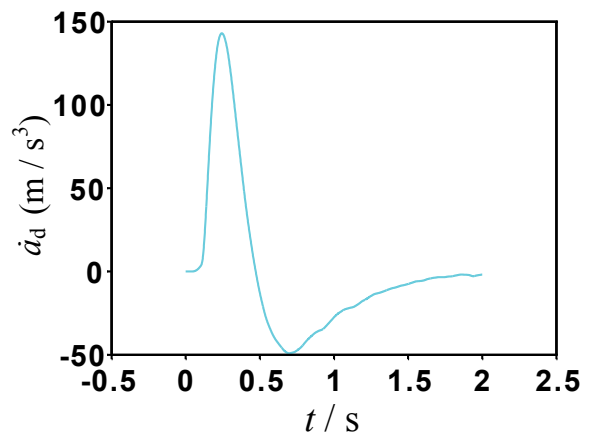

(b)

Figure 7 Experimental waveforms of direct startup with full voltage: (a) Curves of armature current and vehicle speed, (b) Curve of equivalent jerk of generator load

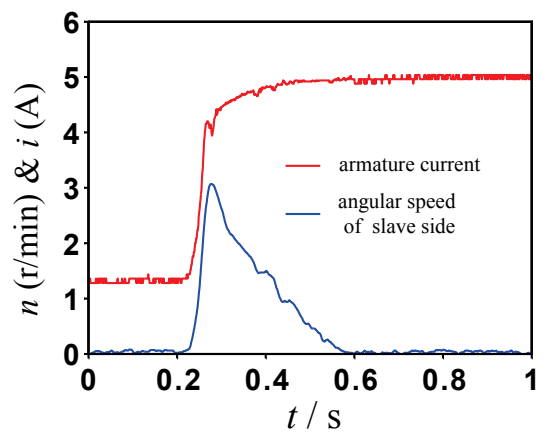

Figure 8 Experimental curves of starting current of drive motor and angular speed of slave side with idle speed $3 \mathrm{~km} / \mathrm{h}$ 


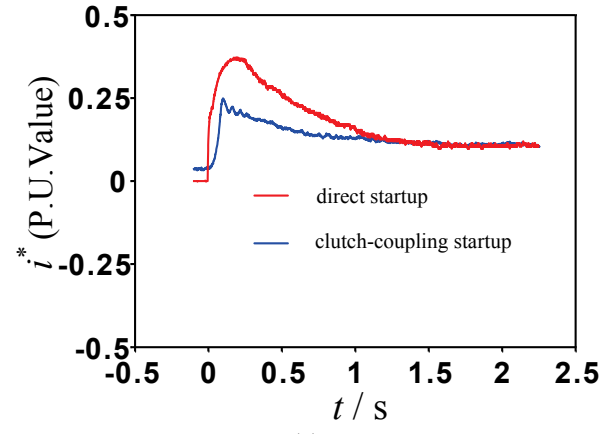

(a)

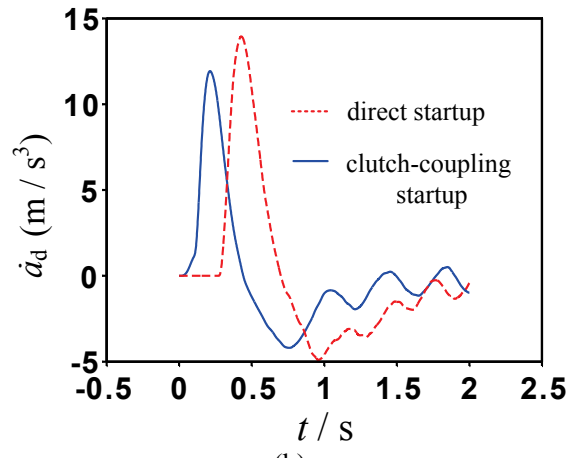

(b)

Figure 9 Experimental comparison of optimized clutch-coupling startup and direct startup: (a) Contrast curves of starting current (b) Contrast curves of equivalent jerk

\section{Conclusions}

A novel bi-stable electromagnetic clutch unit is designed for the wheel-drive application and the working principle and control scheme are discussed in this paper. Then the effectiveness of directly-driven vehicle launch with the assistance of clutch is verified by both simulation and experiment. The results indicate that the shock intensity and electromagnetic impulsion are effectively reduced. Also fast starting process is realized without motor stalling by clutch-coupling startup. The flexible connection between master and slave side through clutchcoupling is a candidate method for improving the shocks induced by direct-startup for in-wheel drive. Further, the idle speed control strategy should be discussed and optimized in consideration of driver's starting intentions as well as the experimental verification of utilizing harmonic fields for energizing the clutch unit in a future work.

\section{Acknowledgements}

This work was supported in part by The National Natural Science Foundation of China (51377063). The authors would like to thank The National Natural Science Foundation of China for the financial support to carry out this research work.

\section{References}

[1] Cheng, K. W. E. Recent development on electric vehicles. // Proceedings of the $3^{\text {rd }}$ International Conference on Power Electronics Systems and Applications / Hong Kong, 2009, pp. 1-5.

[2] Chan, C. C.; Bouscayrol, A.; Chen, K. Electric, hybrid, and fuel-cell vehicles: Architectures and modeling. // IEEE
Transactions on Vehicular Technology. 59, 2(2010), pp. 589-598. DOI: 10.1109/TVT.2009.2033605

[3] Watts, A.; Vallance, A.; Fraser, A. et al. Integrating inwheel motors into vehicles - Real-world experiences. // SAE International Journal of Alternative Powertrains. 1, 1(2012), pp. 289-307. DOI: 10.4271/2012-01-1037

[4] Van, B. K.; Veldpaus, F.; Hofman, T. et al. Fast and smooth clutch engagement control for a mechanical hybrid powertrain. // IEEE Transactions on Control Systems Technology. 22, 4(2014), pp. 1241-1254. DOl: 10.1109/TCST.2013.2279935

[5] Gao, B. Z.; Chen, H.; Lu, X. H.; Sanada, K. Improved optimal controller for startup of AMT trucks in consideration of driver's intention. // International Journal of Automotive Technology. 14, 2(2013), pp. 213-220. DOl: 10.1007/s12239-013-0024-0

[6] Lu, T. L.; Dai, F.; Zhang, J. W.; Wu, M. X. Optimal control of dry clutch engagement based on the driver's starting intentions. // Proceedings of the Institution of Mechanical Engineers, Part D: Journal of Automobile Engineering. 226, 8(2012), pp. 1048-1057. DOI: 10.1177/0954407011435465

[7] Lee, H. D.; Sul, S. K.; Cho, H. S.; Lee, J. M. Advanced gear-shifting and clutching strategy for a parallel-hybrid vehicle. // IEEE Industry Applications Magazine. 6, 6(2000), pp. 26-32. DOI: 10.1109/2943.877837

[8] Tan, L. X.; Ning, L. W.; Zhou, Z. R. Controlled by Computer's Centrifugal Clutch to Add Power with Hydraulic Pressure and Electromagnetism. // Chinese Journal of Mechanical Engineering. 39, 12(2004), pp. 151153. DOI: $10.3901 / J M E .2003 .12 .151$

[9] Achi, P. B. U. Design and testing of an automatic clutch. // Academy Proceedings in Engineering Sciences. 9, 3(1986), pp. 233-238. DOI: 10.1007/bf02811966

[10] Camilleri, R.; Armstrong, P.; Ewin, N. et al. The value of a clutch mechanism in electric vehicles. // Proceedings of the Conference of EVS27 / Barcelona, 2013, pp. 1-11. DOI: 10.1109/evs.2013.6915014

[11] Liu, W. X. Vehicle Design; 2nd ed. Tsinghua University Press, Beijing, China, 2000, pp. 72-74.

[12] Cai, W. L.; Gu, C. L.; Wang, C. H. Novel bistable PM electromagnetic clutch unit for wheel EV drive. // Proceedings of the $17^{\text {th }}$ International Conference on Electrical Machines and Systems / Hang Zhou, 2014, pp. 1164-1167. DOI: 10.1109/icems.2014.7013663

[13] Cai, W. L.; Gu, C. L.; Hu, X. D. Analysis and Design of a Permanent Magnet Bi-Stable Electro-Magnetic Clutch Unit for In-Wheel Electric Vehicle Drives. // Energies. 8, 6(2015), pp. 5589-5612. DOI: 10.3390/en8065598

[14] Huang, Q.; Huang, Z.; Zhou, H. W. Nonlinear optimal and robust speed control for a light-weighted all-electric vehicle. // IET Control Theory \& Applications. 3, 4(2009), pp. 437-444. DOI: 10.1049/iet-cta.2007.0367

[15] Hersey, M. D; Golden, P. L. Rolling Friction, IVAdditional Car Wheel Experiments. // Journal of Tribology. 92, 1(1970), pp. 83-86. DOI: 10.1115/1.3451352

[16] Domenech, A.; Domenech, T.; Cebrian, J. Introduction to the study of rolling friction. // American Journal of Physics. 55, 3(1986), pp. 231-235. DOI: 10.1119/1.15223

[17] Fujii, Y.; Ohgushi, K.; Tojo, T. A proposal for a dynamicresponse-evaluation method for torque transducers. // Measurement Science and Technology. 10, 12(1999), pp. 142-991. DOI: 10.1088/0957-0233/10/12/403

[18] Zhang, J. Z.; Li, B.; Xue, J.; Pan, K. Experimental research on jerk of hybrid electric vehicles. // Chinese Journal of Mechanical Engineering. 44, 4(2008), pp. 87-91. DOI: 10.3901/JME.2008.04.087

[19] Zhang, J.; Chen, L.; Xi, G. System dynamic modelling and adaptive optimal control for automatic clutch engagement of vehicles. // Proceedings of the Institution of Mechanical 
Engineers, Part D: Journal of Automobile Engineering. 216, 12(2002), pp. 983-991. DOI: 10.1243/095440702762508236

[20] Lin, S.; Chang, S.; Li, B. Improving the gear shifts events in automated manual transmission by using an electromagnetic actuator. // Proceedings of the Institution of Mechanical Engineers, Part C: Journal of Mechanical Engineering Science. 229, 9(2015), pp. 1548-1561. DOI: 10.1177/0954406214546204

[21] Duan, C. Analytical Study of a Dog Clutch in Automatic Transmission Application. // SAE International Journal of Passenger Cars-Electronic and Electrical Systems. 7, 3(2014), pp. 1155-1162. DOl: 10.4271/2014-01-1775

[22] Glielmo, L.; Iannelli, L.; Vacca, V. et al. Gearshift control for automated manual transmissions. // IEEE/ASME Transactions on Mechatronics. 11, 1(2006), pp. 17-26. DOI: 10.1109/TMECH.2005.863369

[23] Manfred, M.; Henning, W. Dynamik der kraftfahrzeuge. $1^{\text {st }}$ ed. Springer, Berlin, Germany, 1972, pp. 15-17.

[24] Shmulevich, I.; Mussel, U; Wolf, D. The effect of velocity on rigid wheel performance. // Journal of Terramechanics. 35, 3(1998), pp. 189-207. DOI: 10.1016/S0022-4898(98)000226

\section{Authors' addresses}

\section{Xiong Ping, working towards the Ph.D}

State Key Laboratory of Advanced Electromagnetic Engineering and Technology, Huazhong University of Science \& Technology, Room 6107, Dianjilou, Luoyu road, Wuhan 430074, P. R. China E-mail: px_joey@163.com

\section{Gu Chenglin, Professor}

State Key Laboratory of Advanced Electromagnetic Engineering and Technology, Huazhong University of Science \& Technology, Wuhan 430074, P. R. China

E-mail: clgu@mail.hust.edu.cn 